\title{
Influence of Halogen Substituent on the Self-Assembly and Crystal Packing of Multicomponent Crystals Formed from Ethacridine and Meta-Halobenzoic Acids
}

\author{
Artur Mirocki * and Artur Sikorski * \\ University of Gdańsk, Faculty of Chemistry, W. Stwosza 63, 80-308 Gdańsk, Poland \\ * Correspondence: artur.mirocki@phdstud.ug.edu.pl (A.M.); artur.sikorski@ug.edu.pl (A.S.); \\ Tel.: +48-58-523-5112 (A.M. \& A.S.)
}

Received: 10 December 2019; Accepted: 27 January 2020; Published: 31 January 2020

\begin{abstract}
In order to determine the influence of halogen substituent on the self-assembly of the 6,9-diamino-2-ethoxyacridinium cations and 3-halobenzoate anions in the crystals formed from ethacridine and halobenzoic acids, the series of ethacridinium meta-halobenzoates dihydrates: ethacridinium 3-chlorobenzoate dihydrate (1), ethacridinium 3-bromobenzoate dihydrate (2), and ethacridinium 3-iodobenzoate dihydrate (3), were synthesized and structurally characterized. Single-crystal X-ray diffraction measurements showed that the title compounds crystallized in the monoclinic $P 2_{1} / \mathrm{c}$ space group and are isostructural. In the crystals of title compounds, the ions and water molecules interact via $\mathrm{N}-\mathrm{H} \cdots \mathrm{O}, \mathrm{O}-\mathrm{H} \cdots \mathrm{O}$ and $\mathrm{C}-\mathrm{H} \cdots \mathrm{O}$ hydrogen bonds and $\pi-\pi$ stacking interactions to produce blocks. The relationship between the distance $\mathrm{X} \cdots \mathrm{O}$ between the halogen atom $(\mathrm{X}=\mathrm{Cl}, \mathrm{Br}, \mathrm{I})$ of meta-halobenzoate anion and the $\mathrm{O}$-atom from the ethoxy group of cation from neighbouring blocks and crystal packing is observed in the crystals of the title compounds.
\end{abstract}

Keywords: ethacridine; halobenzoic acids; intermolecular interactions; hydrogen bonds; $\pi-\pi$ stacking interactions; $X \cdots$ O halogen bond; crystal packing

\section{Introduction}

Drug products consist of pharmaceutical ingredients (APIs) and excipients that improve the physical properties of the APIs such as the solubility, stability, pharmacodynamic and pharmacokinetic properties of the product [1-4]. An example of an API is 6,9-diamino-2-ethoxyacridine (ethacridine), a component of a commonly-used drug known as acrinol (ethacridine lactate monohydrate; trade name: rivanol). Acrinol is a bacteriostatic antiseptic drug, which is usually used to treat suppurating infections and infections of the mouth and throat $[5,6]$. Furthermore, ethacridine lactate monohydrate is also used illegally as a highly effective abortifacient for second-trimester pregnancy termination [7].

Synthetic studies of the API derivatives provide new ways to improve their physical properties. In this regard, crystal engineering is of highly importance as it allows the precise design of compounds with desired properties. The APIs are often crystallized in a multicomponent system to explore their ability to form a variety of intermolecular interactions, such as: hydrogen bonds $(\mathrm{O}-\mathrm{H} \cdots \mathrm{O}, \mathrm{N}-\mathrm{H} \cdots \mathrm{O}$, $\mathrm{C}-\mathrm{H} \cdots \mathrm{O}, \mathrm{C}-\mathrm{H} \cdots \pi)$ [8-14], halogen bonds $(\mathrm{X} \cdots \mathrm{X}, \mathrm{X} \cdots \mathrm{O} / \mathrm{N} / \mathrm{S})$ [15-18], $\pi-\pi$ [19-21], lp $\cdots \pi[22,23]$. Among them, halogen bonding is a particularly interesting interaction as it is often crucial in the self-assembly and molecular recognition [24-27]. Halogen bonding is an attractive non-covalent interaction that occurs between a halogen atom and a Lewis base and its directionality and strength are often comparable to those of hydrogen bonds. The strength of such interaction increases in the order of $\mathrm{Cl}<\mathrm{Br}<\mathrm{I}$. 
A search of the Cambridge Structural Database (CSD version 5.40, update August 2019) shows that there are only 3 crystal structures containing ethacridine: 6,9-diamino-2-ethoxyacridinium lactate monohydrate (REFCODE: BIMJUC) [28], and two polymorphs of 6,9-diamino-2-ethoxyacridinium lactate (REFCODES: COVSUD, COVZOE) [29].

In view of the above, as a continuation of our previous studies concerning multicomponent crystals formed from acridines and benzoic acids [30-32], here we describe the synthesis and crystal structure of 6,9-diamino-2-ethoxyacridinium (ethacridinium) meta-halobenzoates dihydrates: ethacridinium 3-chlorobenzoate (1), ethacridinium 3-bromobenzoate (2), and ethacridinium 3-iodobenzoate (3) (Scheme 1). We report a detailed structural analysis of intermolecular interactions featured in these crystals, with an emphasis on those that involve halogen atoms.<smiles>CCOc1ccc2nc3cc(N)ccc3c(N)c2c1</smiles>

6,9-diamino-2-etoxyacridine<smiles>O=C(O)c1cccc(Br)c1</smiles>

3-bromobenzoic acid<smiles>O=C(O)c1cccc(Cl)c1</smiles>

3-chlorobenzoic acid<smiles>O=C(O)c1cccc(I)c1</smiles>

3-iodobenzoic acid

Scheme 1. Chemical structures of the crystals system component reported in this paper.

\section{Materials and Methods}

All the chemicals were purchased from Sigma-Aldrich and used without further purification. Melting points were determined on a Buchi 565 capillary apparatus and were uncorrected.

\subsection{Synthesis of Compounds $\mathbf{1}-\mathbf{3}$}

(a) 6,9-Diamino-2-ethoxyacridinium 3-chlorobenzoate dihydrate (1)

6,9-Diamino-2-ethoxyacridine-DL-lactate monohydrate $(0.05 \mathrm{~g}, 0.138 \mathrm{mmol})$ and 3-chlorobenzoic acid $(0.022 \mathrm{~g}, 0.138 \mathrm{mmol})$ were dissolved in $25 \mathrm{~cm}^{3}$ of an ethanol/water mixture $(2: 3 \mathrm{v} / \mathrm{v})$ and boiled for 40 minutes. The solution was allowed to evaporate for a few days to give yellow crystals of $\mathbf{1}$ (m.p. $\left.=263.6^{\circ} \mathrm{C}\right)$.

(b) 6,9-Diamino-2-ethoxyacridinium 3-bromobenzoate dihydrate (2)

6,9-Diamino-2-ethoxyacridine-DL-lactate monohydrate $(0.05 \mathrm{~g}, 0.138 \mathrm{mmol})$ and 3-bromobenzoic acid $(0.028 \mathrm{~g}, 0.138 \mathrm{mmol})$ were dissolved in $25 \mathrm{~cm}^{3}$ of an ethanol/water mixture $(2: 3 \mathrm{v} / \mathrm{v})$ and boiled for 40 minutes. The clear solution was allowed to evaporate for a few days to give yellow crystals of 2 (m.p. $=271.1^{\circ} \mathrm{C}$ ). 
(c) 6,9-Diamino-2-ethoxyacridinium 3-iodobenzoate dihydrate (3)

6,9-Diamino-2-ethoxyacridine-DL-lactate monohydrate $(0.05 \mathrm{~g}, 0.138 \mathrm{mmol})$ and 3-iodobenzoic acid $(0.034 \mathrm{~g}, 0.138 \mathrm{mmol})$ were dissolved in $25 \mathrm{~cm}^{3}$ of an ethanol/water mixture $(2: 3 \mathrm{v} / \mathrm{v})$ and boiled for 40 minutes. The solution was allowed to evaporate for a few days to give yellow crystals of 3 (m.p. $=280.8^{\circ} \mathrm{C}$ )

\subsection{X-ray Measurements and Refinements}

Good-quality single-crystal specimens of 1-3 were selected for X-ray diffraction experiments at $T$ $=295(2) \mathrm{K}$ (Table 1). They were mounted with epoxy glue at the tip of glass capillaries. Diffraction data were collected on an Oxford Diffraction Gemini R ULTRA Ruby CCD diffractometer with MoK $\alpha$ $(\lambda=0.71073 \AA)$ radiation. In all cases, the lattice parameters were obtained by least-squares fit to the optimized setting angles of the reflections collected by means of CrysAlis CCD [33]. Data were reduced using CrysAlis RED software [33] and applying multi-scan absorption corrections (empirical absorption correction using spherical harmonics, implemented in the SCALE3 ABSPACK scaling algorithm). The structural resolution procedure was carried out using the SHELX package [34]. The structures were solved with direct methods that carried out refinements by full-matrix least-squares on $F^{2}$ using the SHELXL-2017/1 program [34]. All $\mathrm{H}$-atoms bound to $\mathrm{N}$-atoms were located on a difference Fourier map and refined using a riding model, with $\mathrm{N}-\mathrm{H}=0.86 \AA$ and $\mathrm{U}_{\mathrm{iso}}(\mathrm{H})=1.2 \mathrm{U}_{\text {eq }}(\mathrm{C})$. All H-atoms bound to aromatic C-atoms were placed geometrically and refined using a riding model with $\mathrm{C}-\mathrm{H}=0.93 \AA$ and $\mathrm{U}_{\text {iso }}(\mathrm{H})=1.2 \mathrm{U}_{\text {eq }}(\mathrm{C})$. All $\mathrm{H}$-atoms from the methyl group were positioned geometrically and refined using a riding model, with $\mathrm{C}-\mathrm{H}=0.96 \AA$ and $\mathrm{U}_{\mathrm{iso}}(\mathrm{H})=1.5 \mathrm{U}_{\text {eq }}(\mathrm{C})$. All H-atoms from the water molecules were positioned geometrically and refined using a riding model, with $\mathrm{O}-\mathrm{H}=0.85 \AA$ and $\mathrm{U}_{\mathrm{iso}}(\mathrm{H})=1.5 \mathrm{U}_{\mathrm{eq}}(\mathrm{O})$ (DFIX command). All interactions and the Kitaigorodskii type of packing index were calculated using the PLATON program [35]. The ORTEPII [36], PLUTO-78 [37] and Mercury [38] programs were used to prepare the molecular graphics.

\section{Results and Discussion}

Single-crystal X-ray diffraction measurements show that the crystals of 1-3 crystallize in the monoclinic $P 2_{1} / \mathrm{c}$ space group with one unit of 6,9-diamino-2-ethoxyacridine cation, one unit of 3-halobenzoic acid anion and two water molecules (Figure 1 and Table 1). The title compounds are isostructural with each other with the percentage of filled space equal to $67.4 \%, 67.3 \%$ and $66.6 \%$ for compounds 1-3 respectively (the Kitaigorodskii type of packing index), but they are not isostructural with either 6,9-diamino-2-ethoxyacridinium lactate monohydrate (triclinic $P$-1 space group) or 6,9-diamino-2-ethoxyacridinium lactate (triclinic $P-1$ or monoclinic $C 2 / \mathrm{c}$ space groups) [28,29]. In the crystals of compounds 1-3, the bond lengths and angles characterizing the geometry of the ethoxyacridine skeleton [28,29] and 3-halobenzoate acid molecules [30] are typical of these groups of compounds. The lengths of $\mathrm{C}-\mathrm{O}$ bonds range from 1.245(5) to 1.256(5), indicating a proton transfer occurring between the carboxylic group of meta-halobenzoic acid and 6,9-diamino-2-ethoxyacridine. In the crystals of title compounds, the 6,9-diamino-2-ethoxyacridine cation interact with the meta-halobenzoate anion through the $\mathrm{N}_{(9-a m i n o}-\mathrm{H} \cdots \mathrm{O}_{\text {(carboxy) }}$ hydrogen bond $[d(\mathrm{H} 15 \cdots \mathrm{O} 28)=$ $2.15-2.16 \AA$, and $\left.\angle(\mathrm{N} 15-\mathrm{H} 15 \cdots \mathrm{O} 28)=155-156^{\circ}\right]$; whereas one water molecule interacts with both the 6,9-diamino-2-ethoxyacridine cation and the meta-halobenzoate anion via $\mathrm{N}_{\text {(acridine) }}-\mathrm{H} \cdots \mathrm{O}_{(\text {water })}$ $\left[d(\mathrm{H} 10 \cdots \mathrm{O} 31)=1.95 \AA\right.$, and $\left.\angle(\mathrm{N} 10-\mathrm{H} 10 \cdots \mathrm{O} 31)=176-178^{\circ}\right]$ and $\mathrm{O}_{(\text {water })}-\mathrm{H}_{\cdots} \mathrm{O}_{(\text {carboxy })}[d(\mathrm{H} 31 \mathrm{~A} \cdots \mathrm{O} 27)$ $=1.85(4)-1.87(4) \AA$, and $\left.\angle(\mathrm{O} 31-\mathrm{H} 31 \mathrm{~A} \cdots \mathrm{O} 27)=163(4)-167(4)^{\circ}\right]$ hydrogen bonds respectively, to form a centrosymmetric, cyclic heterohexamer bis[ $\cdots$ cation $\cdots$ water $\cdots$ anion $\cdots]$ [ [39] (Table 2, Figure 2). This heterohexamer is not observed in the crystal structures of 6,9-diamino-2-ethoxyacridinium lactate monohydrate and 9-diamino-2-ethoxyacridinium lactate [28,29]. 
a)

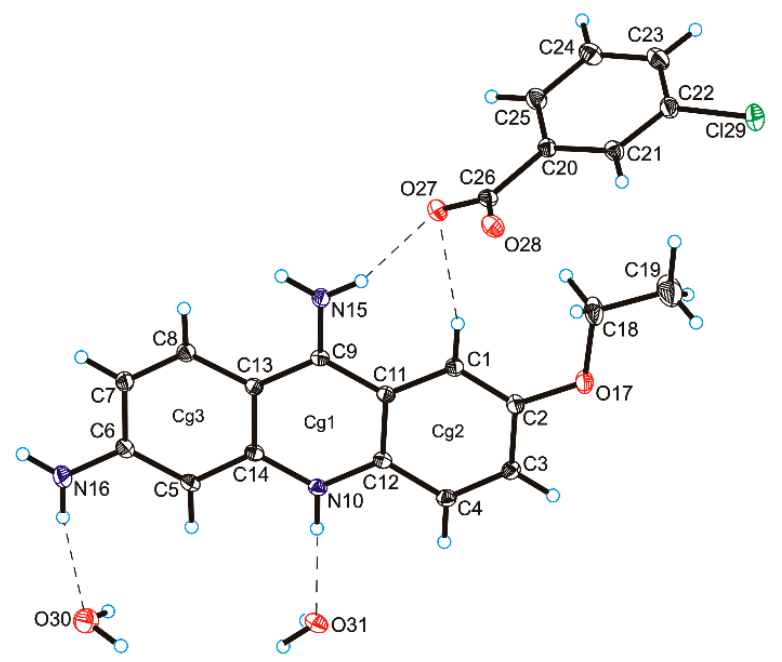

b)

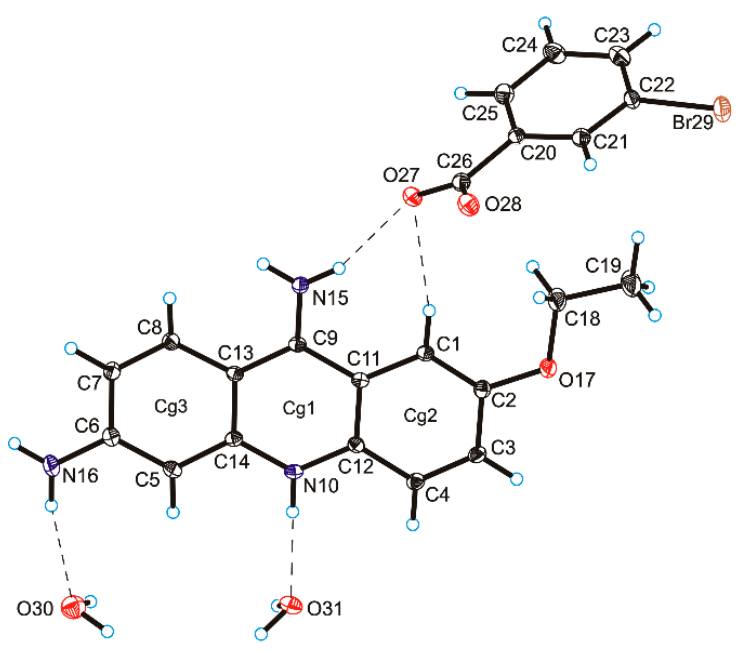

c)

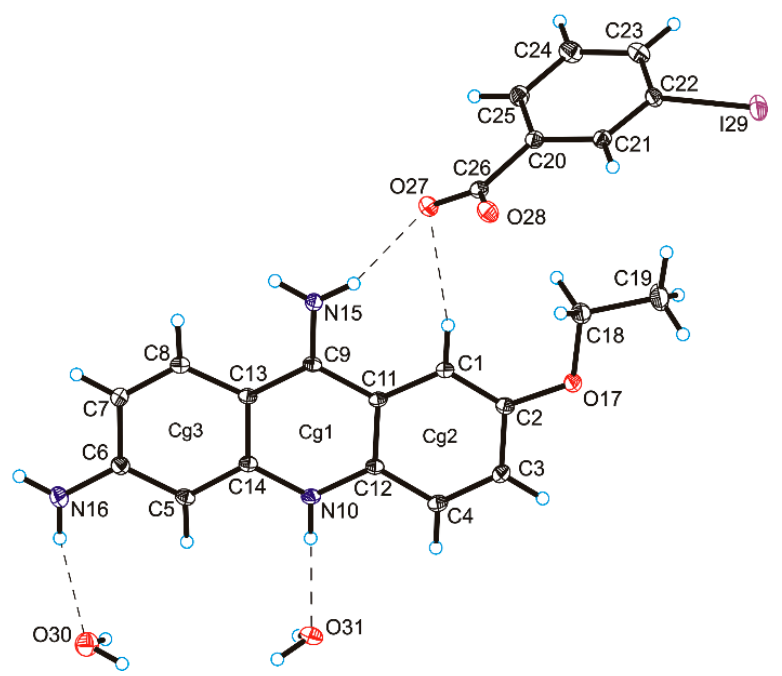

Figure 1. Molecular structures of compounds 1-3 in (a-c), respectively, showing the atom-labelling scheme. $\mathrm{Cg} 1, \mathrm{Cg} 2$ and $\mathrm{Cg} 3$ denote the ring centroids (hydrogen bonds are represented by dashed lines). Displacement ellipsoids are drawn at the $25 \%$ probability level and $\mathrm{H}$ atoms are shown as small spheres of arbitrary radius. 
Table 1. Crystal data and structure refinement parameters for compounds 1-3.

\begin{tabular}{|c|c|c|c|}
\hline Compound & 1 & 2 & 3 \\
\hline Chemical formula & $\mathrm{C}_{22} \mathrm{H}_{24} \mathrm{ClN}_{3} \mathrm{O}_{5}$ & $\mathrm{C}_{22} \mathrm{H}_{24} \mathrm{BrN}_{3} \mathrm{O}_{5}$ & $\mathrm{C}_{22} \mathrm{H}_{24} \mathrm{IN}_{3} \mathrm{O}_{5}$ \\
\hline Formula weight $/ \mathrm{g} \cdot \mathrm{mol}^{-1}$ & 445.89 & 490.35 & 537.34 \\
\hline Crystal system & monoclinic & monoclinic & monoclinic \\
\hline Space group & $P 2_{1} / \mathrm{c}$ & $P 2_{1} / \mathrm{c}$ & $P 2_{1} / \mathrm{c}$ \\
\hline$a / \AA$ & $12.941(4)$ & $13.0933(8)$ & $13.4621(7)$ \\
\hline$b / \AA ̊$ & $8.401(4)$ & $8.3893(7)$ & $8.3911(4)$ \\
\hline$c / \AA$ & $20.580(2)$ & $20.565(5)$ & $20.522(3)$ \\
\hline$\alpha /^{\circ}$ & 90 & 90 & 90 \\
\hline$\beta /^{\circ}$ & $101.475(3)$ & $101.242(7)$ & $100.263(5)$ \\
\hline$\gamma /{ }^{\circ}$ & 90 & 90 & 90 \\
\hline$V / \AA^{3}$ & $2192.6(5)$ & $2215.6(3)$ & $2281.1(2)$ \\
\hline Z & 4 & 4 & 4 \\
\hline$T / \mathrm{K}$ & $295(2)$ & $295(2)$ & $295(2)$ \\
\hline$\lambda_{\mathrm{Mo}} / \AA$ & 0.71073 & 0.71073 & 0.71073 \\
\hline$\rho_{\text {calc }} / \mathrm{g} \cdot \mathrm{cm}^{-3}$ & 1.351 & 1.470 & 1.565 \\
\hline$F(000)$ & 936 & 1008 & 1080 \\
\hline$\mu / \mathrm{mm}^{-1}$ & 0.213 & 1.894 & 1.441 \\
\hline$\theta$ range $/^{\circ}$ & $3.35-25.00$ & $3.17-25.00$ & $3.35-25.00$ \\
\hline Completness $\theta / \%$ & 99.7 & 99.8 & 99.8 \\
\hline Reflections collected & 15401 & 14566 & 15803 \\
\hline Reflections unique & $3855\left[R_{\text {int }}=0.0689\right]$ & $3893\left[\mathrm{R}_{\mathrm{int}}=0.0881\right]$ & $3999\left[R_{\text {int }}=0.0562\right]$ \\
\hline Data/restraints/parameters & $3855 / 6 / 293$ & $3893 / 6 / 293$ & $3999 / 6 / 293$ \\
\hline Goodness of fit on $F^{2}$ & 1.007 & 0.984 & 1.009 \\
\hline Final $R_{1}$ value $(I>2 \sigma(I))$ & 0.0593 & 0.0539 & 0.0409 \\
\hline Final $w \mathrm{R}_{2}$ value $(I>2 \sigma(I))$ & 0.1464 & 0.1010 & 0.0771 \\
\hline $\begin{array}{c}\text { Final } R_{1} \text { value } \\
\text { (all data) }\end{array}$ & 0.1114 & 0.1320 & 0.0779 \\
\hline $\begin{array}{l}\text { Final } w \mathrm{R}_{2} \text { value } \\
\quad \text { (all data) }\end{array}$ & 0.1821 & 0.1263 & 0.0900 \\
\hline CCDC number & 1968938 & 1968940 & 1968939 \\
\hline
\end{tabular}

These heterohexames feature $\pi-\pi$ stacking formed between ethacridinium cations with centroid...centroid distance $[d(\mathrm{Cg} \cdots \mathrm{Cg})]$ ranging from $3.583(2)$ to $3.773(2) \AA$, and weak $\mathrm{C}_{\text {(acridine) }}-\mathrm{H} \cdots \mathrm{O}_{\text {(carboxy) }}$ hydrogen bonds between a $\mathrm{C} 1$ atom of ethacridinium cation and an O-atom from the carboxylate group of meta-halobenzoate anion are also observed. The distances between donor and acceptor in all the aforementioned interactions are similar, as is the distance between the mean planes of ethacridine skeletons (3.42-3.43 ) (Table 2, Figure 2).

An analysis of interactions between the neighbouring heterohexamers indicates that the $\pi-\pi$ stacking interactions, with $d(\mathrm{Cg} \cdots \mathrm{Cg})$ distance ranging from 3.583 to $3.771 \AA$, can be observed between aromatic rings of ethacridine moieties. As a result, the $\pi-\pi$ stacked columns of the

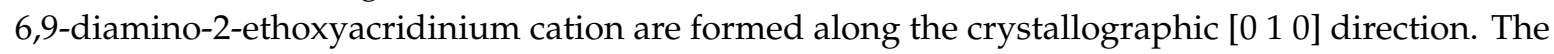
distance between the mean planes of ethacridine skeletons of adjacent heterohexamers in these columns is $3.47,3.44$ and $3.42 \AA$, for compounds 1-3 respectively. The adjacent heterohexamers are also linked by an $\mathrm{O}_{(\text {water) }}-\mathrm{H} \cdots \mathrm{O}_{\text {(water) }}$ hydrogen bond between water molecules and through an $\mathrm{O}_{\text {(carboxy) }}-\mathrm{H} \cdots \mathrm{O}_{\text {(water) }}$ hydrogen bond between water molecules and meta-halobenzoate anions to produce blocks along the $c$-axis (Table 2$)$. As a consequence, we can observe a cyclic synthon $[\cdots(\mathrm{O} \cdots$ $\left.\mathrm{C} \cdots \mathrm{O})^{-} \cdots \mathrm{H}-\mathrm{O}-\mathrm{H} \cdots \mathrm{O}^{-} \cdots \mathrm{H}-\mathrm{O}-\mathrm{H} \cdots \mathrm{O}-\mathrm{H} \cdots\right]$ and a hydrogen-bonded supramolecular tape motif (Figure 3) [40-44]. 
a)

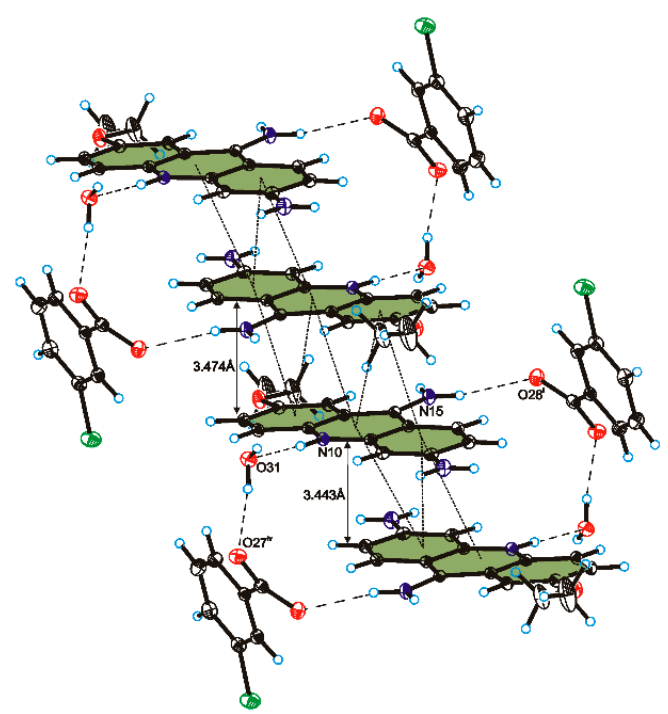

b)

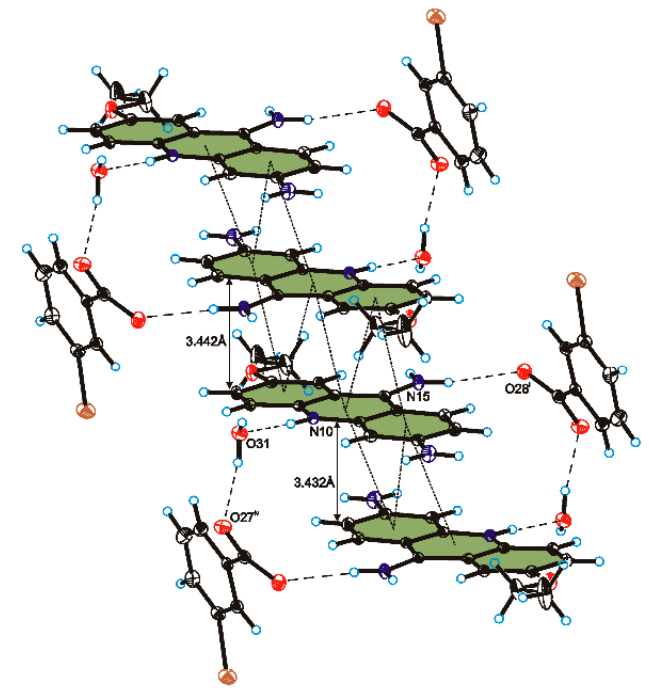

c)

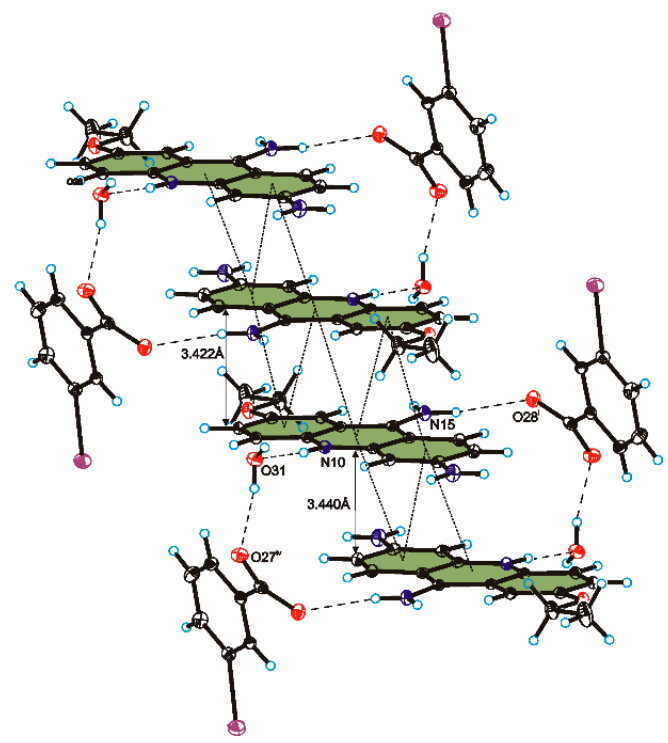

Figure 2. Heterohexamers formed by ethacridinium cations, meta-halobenzoate anions and water molecules and $\pi-\pi$ stacking interactions between them in compounds 1-3 shown in (a-c), respectively (hydrogen bonds are represented by dashed lines, whereas $\pi-\pi$ stacking interactions are represented by dotted lines). 
Table 2. Hydrogen bonds geometry for compounds 1-3.

\begin{tabular}{|c|c|c|c|c|c|}
\hline Compound & D-H $\cdots A$ & $d(\mathrm{D}-\mathrm{H})[\AA]$ & $d(\mathbf{H} \cdots \mathbf{A})[\AA ̊]$ & $d(\mathbf{D} \cdots \mathbf{A})[\AA]$ & $\angle \mathrm{D}-\mathrm{H} \cdots \mathbf{A}\left({ }^{\circ}\right)$ \\
\hline \multirow{9}{*}{1} & $\mathrm{~N}(10)-\mathrm{H}(10) \cdots \mathrm{O}(31)$ & 0.86 & 1.95 & $2.810(3)$ & 178 \\
\hline & $\mathrm{N}(15)-\mathrm{H}(15 \mathrm{~A}) \cdots \mathrm{O}(28)^{\mathrm{i}}$ & 0.86 & 2.16 & $2.957(3)$ & 155 \\
\hline & $\mathrm{N}(15)-\mathrm{H}(15 \mathrm{~B}) \cdots \mathrm{O}(27)$ & 0.86 & 2.13 & $2.960(3)$ & 161 \\
\hline & $\mathrm{N}(16)-\mathrm{H}(16 \mathrm{~A}) \cdots \mathrm{O}(30)$ & 0.86 & 2.17 & $3.016(4)$ & 168 \\
\hline & $\mathrm{O}(30)-\mathrm{H}(30 \mathrm{~A}) \cdots \mathrm{O}(31)^{\mathrm{ii}}$ & $0.84(3)$ & $2.01(3)$ & $2.824(4)$ & $163(3)$ \\
\hline & $\mathrm{O}(30)-\mathrm{H}(30 \mathrm{~B}) \cdots \mathrm{O}(28)^{\mathrm{iii}}$ & $0.84(3)$ & $2.00(3)$ & $2.835(4)$ & $177(7)$ \\
\hline & $\mathrm{O}(31)-\mathrm{H}(31 \mathrm{~A}) \cdots \mathrm{O}(27)^{\mathrm{iv}}$ & $0.84(3)$ & $1.87(3)$ & $2.689(3)$ & $167(4)$ \\
\hline & $\mathrm{O}(31)-\mathrm{H}(31 \mathrm{~B}) \cdots \mathrm{O}(28)^{\mathrm{iii}}$ & $0.85(3)$ & $1.94(3)$ & $2.775(3)$ & $169(3)$ \\
\hline & $\mathrm{C}(1)-\mathrm{H}(1) \cdots \mathrm{O}(27)$ & 0.93 & 2.56 & 3.471(4) & 167 \\
\hline \multicolumn{6}{|c|}{ Symmetry code: (i) $1-x, 1 / 2+y, 1 / 2-z$; (ii) $1-x, 1 / 2+y, 3 / 2-z$; (iii) $1-x, 1-y, 1-z$; (iv) $x, 3 / 2-y, 1 / 2+z$. } \\
\hline \multirow{9}{*}{2} & $\mathrm{~N}(10)-\mathrm{H}(10) \cdots \mathrm{O}(31)$ & 0.86 & 1.95 & $2.813(4)$ & 177 \\
\hline & $\mathrm{N}(15)-\mathrm{H}(15 \mathrm{~A}) \cdots \mathrm{O}(28)^{\mathrm{i}}$ & 0.86 & 2.15 & $2.950(4)$ & 156 \\
\hline & $\mathrm{N}(15)-\mathrm{H}(15 \mathrm{~B}) \cdots \mathrm{O}(27)$ & 0.86 & 2.13 & $2.954(4)$ & 160 \\
\hline & $\mathrm{N}(16)-\mathrm{H}(16 \mathrm{~A}) \cdots \mathrm{O}(30)$ & 0.86 & 2.18 & $3.026(6)$ & 168 \\
\hline & $\mathrm{O}(30)-\mathrm{H}(30 \mathrm{~A}) \cdots \mathrm{O}(31)^{\mathrm{ii}}$ & $0.85(4)$ & $1.98(4)$ & $2.811(6)$ & $167(4)$ \\
\hline & $\mathrm{O}(30)-\mathrm{H}(30 \mathrm{~B}) \cdots \mathrm{O}(28)^{\mathrm{iii}}$ & $0.86(3)$ & $1.98(3)$ & $2.835(5)$ & $173(5)$ \\
\hline & $\mathrm{O}(31)-\mathrm{H}(31 \mathrm{~A}) \cdots \mathrm{O}(27)^{\mathrm{iv}}$ & $0.85(4)$ & $1.85(4)$ & $2.679(5)$ & $163(5)$ \\
\hline & $\mathrm{O}(31)-\mathrm{H}(31 \mathrm{~B}) \cdots \mathrm{O}(28)^{\mathrm{iii}}$ & $0.85(4)$ & $1.93(4)$ & $2.763(5)$ & $169(5)$ \\
\hline & $\mathrm{C}(1)-\mathrm{H}(1) \cdots \mathrm{O}(27)$ & 0.93 & 2.55 & $3.465(5)$ & 168 \\
\hline \multicolumn{6}{|c|}{ Symmetry code: (i) $1-x, 1 / 2+y, 1 / 2-z$; (ii) $1-x, 1 / 2+y, 3 / 2-z$; (iii) $1-x, 1-y, 1-z$; (iv) $x, 3 / 2-y, 1 / 2+z$. } \\
\hline \multirow{9}{*}{3} & $\mathrm{~N}(10)-\mathrm{H}(10) \cdots \mathrm{O}(31)$ & 0.86 & 1.95 & $2.807(4)$ & 176 \\
\hline & $\mathrm{N}(15)-\mathrm{H}(15 \mathrm{~A}) \cdots \mathrm{O}(28)^{\mathrm{i}}$ & 0.86 & 2.16 & $2.964(4)$ & 156 \\
\hline & $\mathrm{N}(15)-\mathrm{H}(15 \mathrm{~B}) \cdots \mathrm{O}(27)$ & 0.86 & 2.13 & $2.948(4)$ & 160 \\
\hline & $\mathrm{N}(16)-\mathrm{H}(16 \mathrm{~A}) \cdots \mathrm{O}(30)$ & 0.86 & 2.19 & $3.031(5)$ & 166 \\
\hline & $\mathrm{O}(30)-\mathrm{H}(30 \mathrm{~A}) \cdots \mathrm{O}(31)^{\mathrm{ii}}$ & $0.84(4)$ & $2.00(4)$ & $2.816(5)$ & $165(4)$ \\
\hline & $\mathrm{O}(30)-\mathrm{H}(30 \mathrm{~B}) \cdots \mathrm{O}(28)^{\mathrm{iii}}$ & $0.83(3)$ & $2.00(3)$ & $2.830(5)$ & $172(5)$ \\
\hline & $\mathrm{O}(31)-\mathrm{H}(31 \mathrm{~A}) \cdots \mathrm{O}(27)^{\mathrm{iv}}$ & $0.83(4)$ & $1.87(4)$ & $2.684(4)$ & $164(4)$ \\
\hline & $\mathrm{O}(31)-\mathrm{H}(31 \mathrm{~B}) \cdots \mathrm{O}(28)^{\mathrm{iii}}$ & $0.83(3)$ & $1.93(3)$ & $2.757(4)$ & $171(3)$ \\
\hline & $\mathrm{C}(1)-\mathrm{H}(1) \cdots \mathrm{O}(27)$ & 0.93 & 2.54 & $3.455(4)$ & 168 \\
\hline
\end{tabular}

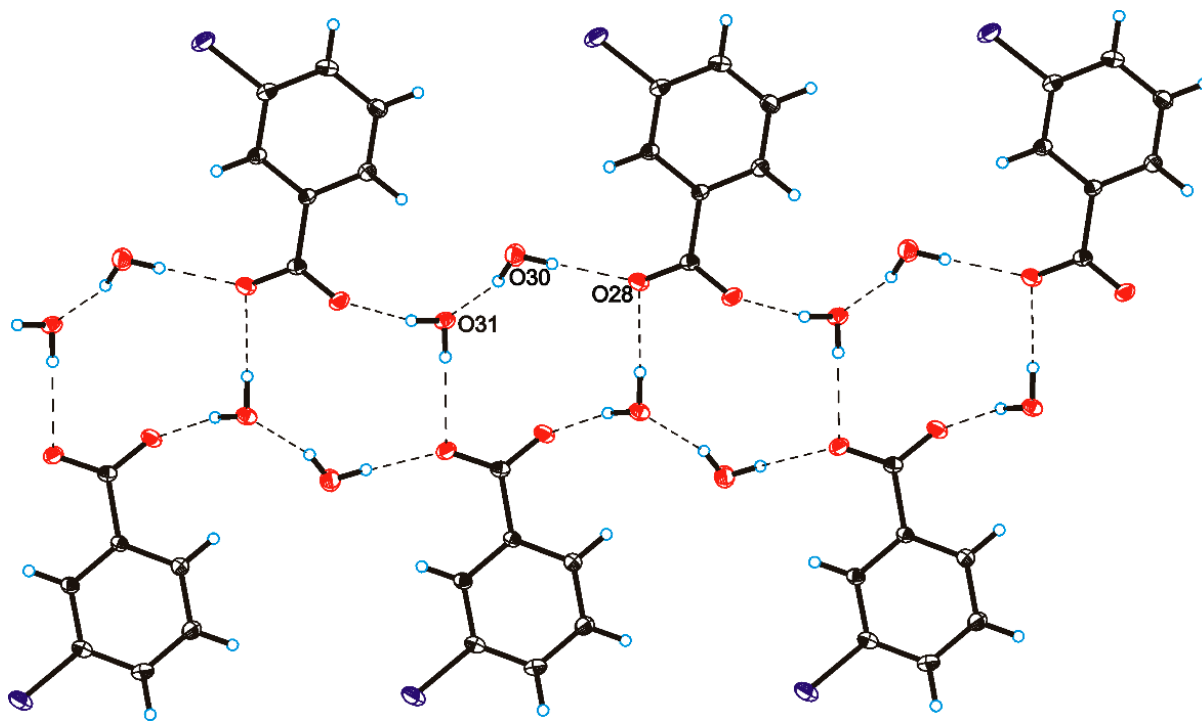

Figure 3. Supramolecular tape motif in the crystal packing of compound 3 (hydrogen bonds are represented by dashed lines).

In these blocks, we can also observe the $\mathrm{N}_{(6-a m i n o)}-\mathrm{H} \cdots \mathrm{O}_{\text {(carboxy) }}$ hydrogen bond between amino group substituted on the carbon atom $\mathrm{C} 6$ of ethacridinium moiety and the $\mathrm{O}$-atom from the carboxylate group of anion (Figure 4). The distances between donor and acceptor atoms engaged in these hydrogen bonds are similar in the crystals of compounds 1-3 (Table 2). 
a)

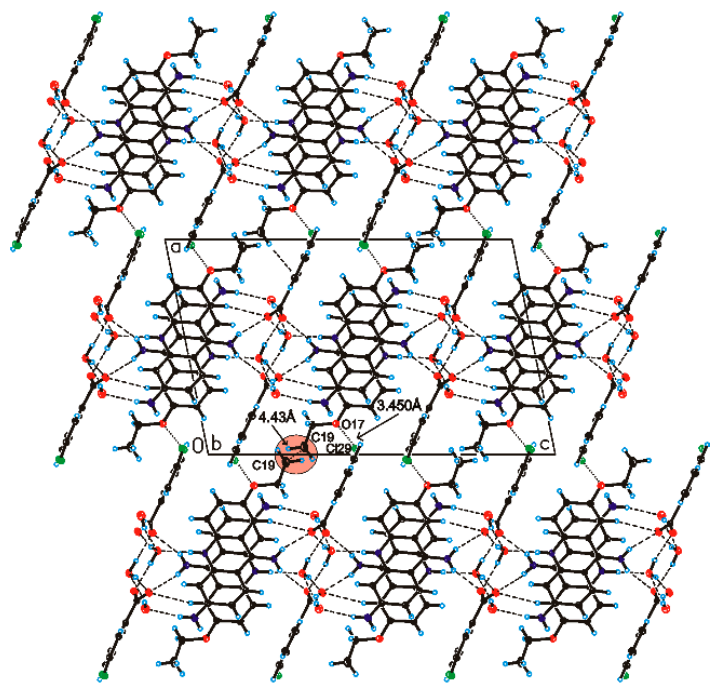

b)

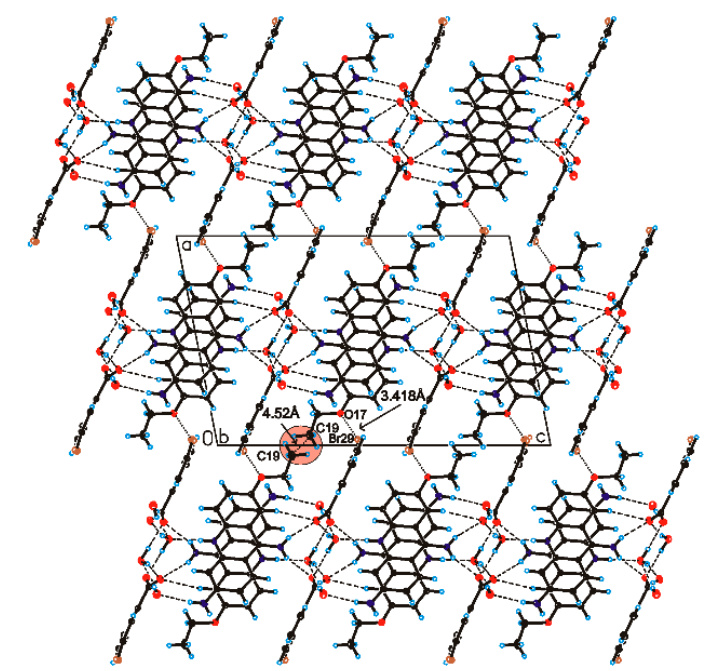

c)

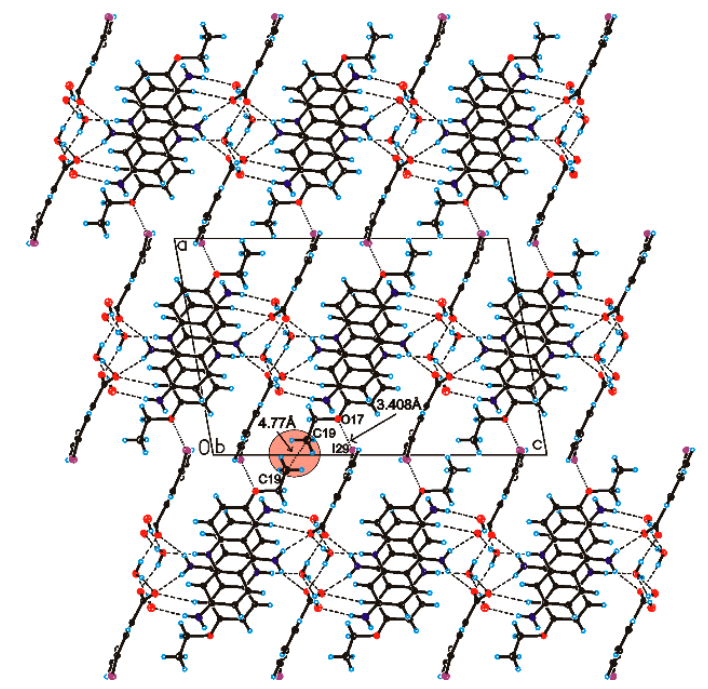

Figure 4. Crystal packing of compounds 1-3 shown in (a-c), respectively, viewed along the $b$-axis (hydrogen bonds and halogen bonds are represented by dashed lines, whereas C19... C19 (highlighted in pink) and X29 ․ O17 distances are represented by dotted lines). 
In the packing of the crystals of title compounds, we can observe that distance between the halogen atom substituted in the meta- position of the aromatic ring of acid and the O-atom from the ethoxy group of cation $[d(\mathrm{X} \cdots \mathrm{O})]$ from neighbouring blocks decreases with decreasing electronegativity of the halogen atom, and is $d(\mathrm{Cl} 29 \cdots \mathrm{O} 17)=3.450(3) \AA, d(\mathrm{Br} 29 \cdots \mathrm{O} 17)=3.418(3) \AA$ and $d(\mathrm{I} 29 \cdots \mathrm{O} 17)=3.408(3)$ $\AA$ (Figure 4). It is longer than the sum of the van der Waals radii of chlorine and oxygen atoms (3.27 $\AA$ ) and bromine and oxygen atoms (3.37 $\AA$ ); however, it is shorter than the sum of the van der Waals radii of iodine and oxygen atoms $(3.50 \AA)$. As a result, the weak X... O halogen bond is observed only in the crystal of compound 3 . At the same time, the distance between adjacent blocks increases with decreasing $d(\mathrm{X} \cdots \mathrm{O})$ distance (the distance between the closest methyl groups from neighbouring blocks (distance between C19...C19 atoms) is 4.43, 4.52 and $4.77 \AA$ for compounds 1-3, respectively) (Figure 4).

Other relationships are observed in isostructural unsolvated co-crystals formed from acridine and meta-halobenzoic acids [30]. Due to the fact that in the crystals of these complexes the solvent molecules are absent, acridine and meta-halobenzoic acids molecules are linked through $\mathrm{O}_{\text {(carboxy) }}-\mathrm{H} \cdots \mathrm{N}_{\text {(acridine) }}$ and $\mathrm{C}_{\text {(acridine) }}-\mathrm{H} \cdots \mathrm{O}_{\text {(carboxy) }}$ hydrogen bonds to form centrosymmetric, cyclic heterotetramers $\operatorname{bis}[\cdots$ acridine $\cdots$ benzoic acid $\cdots]$ [39]. The neighbouring heterotetramers are linked via $\pi-\pi$ stacking interactions between aromatic rings of acridine moieties, and $\mathrm{C}_{\text {(acridine) }}-\mathrm{H} \cdots \mathrm{O}_{\text {(carboxy) }}$ and $\mathrm{C}_{(\text {acridine })}-\mathrm{H} \cdots \mathrm{X}$ hydrogen bonds and produce blocks. The geometrical parameters characterized the aforementioned interactions (including the distance between the mean planes of adjacent acridine skeletons of neighbouring heterotetramers equal to $c a$. 3,56 $⿱$ ) ) are similar in all cases. However, between neighbouring blocks $\mathrm{X} \cdot \mathrm{O}$ contact occurs between the halogen atom and the O-atom from the carboxy group of acids, and the $d(\mathrm{X} \cdots \mathrm{O})$ distance increases with the decreasing of electronegativity of the halogen atom $[d(\mathrm{Cl} \cdots \mathrm{O})=3.399(3) \AA, d(\mathrm{Br} \cdots \mathrm{O})=3.415(3) \AA$ and $d(\mathrm{I} \cdots \mathrm{O})=3.468(3) \AA]$, as does the distance between neighbouring blocks. Simultaneously, the strength of the $\mathrm{C}_{(\text {acid }}-\mathrm{H} \cdots$ X hydrogen bond decreases, which also links the neighbouring blocks and the the Kitaigorodskii type of packing index (with the percentage of filled space equal to 68.0, 67.9 and $67.4 \%$ for complexes formed from 3-chloro, 3-bromo and 3-iodobenzoic acid respectively).

\section{Conclusions}

Considering the above, we can conclude that type of halogen atom substituted in the metaposition in the benzoate ion influences the crystal packing of the title compounds. The $d(\mathrm{X} \cdots \mathrm{O})$ distance between the halogen atom substituted in the meta- position of the aromatic ring of acid and the O-atom from the ethoxy group of cation from neighbouring blocks decreases with the decreasing electronegativity of the halogen atom in the order $\mathbf{1}>\mathbf{2}>\mathbf{3}$, as does the distance between the mean planes of adjacent acridine skeletons of neighbouring heterohexamers. At the same time, the distance between adjacent blocks increases in the order $1<2<3$, which explains the decreasing of the Kitaigorodskii type of packing index of compound 3 by about $1 \%$ compared to the other compounds. The weak X $\cdots$ O halogen bond is observed only in the crystal of compound 3 . This confirms the general tendency that in multicomponent crystals formed from chloro- and bromo-substituted acids, the molecules/ions of acid are hydrogen-bonded, whereas those formed from iodo-substituted acids are halogen bonded [17-20,26-29].

Future studies are expected to confirm the conclusions that can be drawn from this research. In order to determine the influence of other substituents in the benzoic acid molecule, such as - $\mathrm{COOH}$, $-\mathrm{OH},-\mathrm{NH}_{2}$ and $-\mathrm{NO}_{2}$ on the self-assembly processes, we plan to obtain other multicomponent crystals formed from ethacridine and other mono- or poly- substituted benzoic acids.

The results of our research may be of practical importance from the crystal engineering point of view for the design of new pharmaceutical multicomponent crystals formed from ethacridine or other acridine derivatives.

Author Contributions: Conceptualization, A.M. and A.S.; methodology, A.M. and A.S.; software, A.M. and A.S.; formal analysis, A.M. and A.S.; investigation, A.M. and A.S.; writing-original draft preparation, A.M. and A.S.; visualization, A.M. and A.S.; project administration, A.M. and A.S. All authors have read and agreed to the published version of the manuscript. 
Funding: This research was funded by: Research of Young Scientists grant (BMN) no. 538-8220-B290-18, 539-8220-B290-19 (University of Gdańsk) and DS 530-8228-D738-19 (University of Gdańsk).

Conflicts of Interest: The authors declare no conflict of interest.

\section{References}

1. Pilcer, G.; Amighi, K. Formulation strategy and use of excipients in pulmonary drug delivery. Int. J. Pharm. 2010, 392, 1-19. [CrossRef] [PubMed]

2. Jivraj, M.; Martini, L.G.; Thomson, C.M. An overview of the different excipients useful for the direct compression of tablets. Pharm. Sci. Tech. Today 2000, 3, 58-63. [CrossRef]

3. Illum, L. Chitosan and its use as a pharmaceutical excipient. Pharm. Res. 1998, 15, 1326-1331. [CrossRef] [PubMed]

4. Baldrick, P. The safety of chitosan as a pharmaceutical excipient. Regul. Toxicol. Pharm. 2010, 56, $290-299$. [CrossRef] [PubMed]

5. Oie, S.; Kamiya, A. Bacterial contamination of commercially available ethacridine lactate (acrinol) product. J. Hosp. Infect. 1996, 34, 51-58. [CrossRef]

6. Koelzer, S.C.; Held, H.; Toennes, S.W.; Verhoff, M.A.; Wunder, C. Self-induced illegal abortion with Rivanol@: A medicolegal-toxicological case report. Forensic Sci. Int. 2016, 268, e18-e22. [CrossRef]

7. Chen, C.; Lin, F.; Wang, X.; Jiang, Y.; Wu, S. Mifepristone combined with ethacridine lactate for the second-trimester pregnancy termination in women with placenta previa and/or prior cesarean deliveries. Arch. Gynecol. Obstet. 2017, 295, 119-124. [CrossRef]

8. Aakeröy, C.B.; Fasulo, M.; Schultheiss, N.; Desper, J.; Moore, C. Structural competition between hydrogen bonds and halogen bonds. J. Am. Chem. Soc. 2007, 129, 13772-13773. [CrossRef]

9. Desiraju, G.R. Designer crystals: Intermolecular interactions, network structures and supramolecular synthons. Chem. Commun. 1997, 16, 1475-1482. [CrossRef]

10. Thomas, S.P.; Pavan, M.S.; Guru Row, T.N. Charge density analysis of ferulic acid: Robustness of a trifurcated C-H ... O hydrogen bond. Cryst. Growth Des. 2012, 12, 6083-6091. [CrossRef]

11. Tothadi, S.; Desiraju, G.R. Designing ternary cocrystals with hydrogen bonds and halogen bonds. Chem. Commun. 2013, 49, 7791-7793. [CrossRef] [PubMed]

12. Weiss, H.-C.; Bläser, D.; Boese, R.; Doughan, B.M.; Haley, M.M. C-H $\cdots \pi$ interactions in ethynylbenzenes: The crystal structures of ethynylbenzene and 1,3,5-triethynylbenzene, and a redetermination of the structure of 1,4-diethynylbenzene. Chem. Comm. 1997, 18, 1703-1704. [CrossRef]

13. Steiner, T. C-H...O hydrogen bonding in crystals. Crystallogr. Rev. 2003, 9, 177-228. [CrossRef]

14. Nishio, M. CH/ $\pi$ hydrogen bonds in crystals. CrystEngComm 2004, 6, 130-158. [CrossRef]

15. Aakeröy, C.B.; Sinha, A.S.; Chopade, P.D.; Desper, J. Halogen bonding or close packing? Examining the structural landscape in a series of $\mathrm{Cu}$ (ii)-acac complexes. Dalton T. 2011, 40, 12160-12168. [CrossRef]

16. Aakeröy, C.B.; Chopade, P.D.; Desper, J. Establishing a hierarchy of halogen bonding by engineering crystals without disorder. Cryst. Growth Des. 2013, 13, 4145-4150. [CrossRef]

17. Mukherjee, A.; Tothadi, S.; Desiraju, G.R. Halogen bonds in crystal engineering: Like hydrogen bonds yet different. Acc. Chem. Res. 2014, 47, 2514-2524. [CrossRef]

18. Lommerse, J.P.M.; Stone, A.J.; Taylor, R.; Allen, F.H. The nature and geometry of intermolecular interactions between halogens and oxygen or nitrogen. J. Am. Chem. Soc. 1996, 118, 3108-3116. [CrossRef]

19. Blake, A.J.; Champness, N.R.; Khlobystov, A.N.; Lemenovskii, D.A.; Li, W.-S.; Schröder, M. Crystal engineering: The effects of $\pi-\pi$ interactions in copper(I) and silver(I) complexes of 2,7-diazapyrene. Chem. Comm. 1997, 15, 1339-1340. [CrossRef]

20. Huang, J.; Kertesz, M. Intermolecular covalent $\pi-\pi$ bonding interaction indicated by bond distances, energy bands, and magnetism in biphenalenyl biradicaloid molecular crystal. J. Am. Chem. Soc. 2007, 129, 1634-1643. [CrossRef]

21. Hunter, C.A.; Sanders, J.K.M. The nature of $\pi-\pi$ interactions. J. Am. Chem. Soc. 1990, 112, 5525-5534. [CrossRef]

22. Shukla, R.; Mohan, T.P.; Vishalakshi, B.; Chopra, D. Experimental and theoretical analysis of lp $\cdots \pi$ intermolecular interactions in derivatives of 1,2,4-triazoles. CrystEngComm 2014, 16, 1702-1713. [CrossRef] 
23. Nelyubina, Y.V.; Barzilovich, P.Y.; Antipin, M.Y.; Aldoshin, S.M.; Lyssenko, K.A. Cation- $\pi$ and lone pair- $\pi$ interactions combined in one: The first experimental evidence of $\left(\mathrm{H}_{3} \mathrm{O}-\mathrm{lp}\right)^{+} \cdots \pi$-system binding in a crystal. ChemPhysChem 2011, 12, 2895-2898. [CrossRef] [PubMed]

24. Auffinger, P.; Hays, F.A.; Westhof, E.; Ho, P.S. Halogen bonds in biological molecules. Pro. Natl. Acad. Sci. USA 2004, 101, 16789-16794. [CrossRef]

25. Meyer, F.; Dubois, P. Halogen bonding at work: Recent applications in synthetic chemistry and materials science. CrystEngComm 2013, 15, 3058-3071. [CrossRef]

26. Cavallo, G.; Metrangolo, P.; Milani, R.; Pilati, T.; Priimagi, A.; Resnati, G.; Terraneo, G. The halogen bond. Chem. Rev. 2016, 116, 2478-2601. [CrossRef]

27. Metrangolo, P.; Meyer, F.; Pilati, T.; Resnati, G.; Terraneo, G. Halogen bonding in supramolecular chemistry. Angew. Chem. Int. Edit. 2008, 47, 6114-6127. [CrossRef]

28. Neidle, S.; Aggarwal, A. Nucleic Acid Binding Drugs. The Structure of 3,9-Diamino-7-ethoxyacridine (Rivanol) as the Lactate Monohydrate Salt. Acta Crystallogr. 1982, B38, 2420-2424. [CrossRef]

29. Fujii, K.; Uekusa, H.; Itoda, N.; Hasegawa, G.; Yonemochi, E.; Terada, K.; Pan, Z.; Harris, K.D.M. Physicochemical understanding of polymorphism and solid-state dehydration/rehydration processes for the pharmaceutical material acrinol, by Ab initio powder X-ray diffraction analysis and other techniques. J. Phys. Chem. C 2010, 114, 580-586. [CrossRef]

30. Kowalska, K.; Trzybiński, D.; Sikorski, A. Influence of the halogen substituent on the formation of halogen and hydrogen bonding in co-crystal formed from acridine and benzoic acids. CrystEngComm 2015, 17, 7199-7212. [CrossRef]

31. Sikorski, A.; Trzybiński, D. Synthesis and structural characterization of a cocrystal salt containing acriflavine and 3,5-dinitrobenzoic acid. Tetrahedron Lett. 2014, 55, 2253-2255. [CrossRef]

32. Sikorski, A.; Trzybiński, D. Networks of intermolecular interactions involving nitro groups in the crystals of three polymorphs of 9-aminoacridinium 2,4-dinitrobenzoate -2,4-dinitrobenzoic acid. J. Mol. Struct. 2013, 1049, 90-98. [CrossRef]

33. CrysAlis CCD and CrysAlis RED, Version 1.171.36.24; Oxford Diffraction Ltd.: Yarnton, England, 2012.

34. Sheldrick, G.M. A Short History of SHELX. Acta Crystallogr. 2008, A64, 112-122. [CrossRef] [PubMed]

35. Spek, A.L. Structure validation in chemical crystallography. Acta Crystallogr. 2009, D65, 148-155. [CrossRef] [PubMed]

36. Johnson, C.K. ORTEP II, Report ORNL-5138; Oak Ridge National Laboratory: OakRidge, TN, USA, 1976.

37. Motherwell, S.; Clegg, S. PLUTO-78, Program for Drawing and Molecular Structure; University of Cambridge: Cambridge, UK, 1978.

38. Macrae, C.F.; Bruno, I.J.; Chisholm, J.A.; Edgington, P.R.; McCabe, P.; Pidcock, E.; Rodriguez-Monge, L.; Taylor, R.; van de Streek, J.; Wood, P.A. Mercury CSD 2.0-New Features for the Visualization and Investigation of Crystal Structures. J. Appl. Crystallogr. 2008, 41, 466-470. [CrossRef]

39. Wang, J.-R.; Ye, C.; Mei, X. Structural and physicochemical aspects of hydrochlorothiazide co-crystals. CrystEngComm 2014, 16, 6996-7003. [CrossRef]

40. Smith, G.; Wermuth, U.D. Bis (guanidinium) 4,5-dichlorophthalate monohydrate. Acta Crystallogr. 2011, E67, o1645. [CrossRef]

41. Rajam, A.; Thomas Muthiah, P.; Butcher, R.J.; Zeller, M. Crystal structure of 4-amino-5-chloro-2, 6-dimethylpyrimidinium thiophene-2, 5-dicarboxylate. Acta Crystallogr. 2016, E72, 1043-1046. [CrossRef]

42. Mukherjee, A.; Dixit, K.; Sarma, S.P.; Desiraju, G.R. Aniline-phenol recognition: From solution through supramolecular synthons to cocrystals. IUCr 2014, 1, 228-239. [CrossRef]

43. Kaur, R.; Gautam, R.; Cherukuvada, S.; Guru Row, T.N. Do carboximide-carboxylic acid combinations form co-crystals? The role of hydroxyl substitution on the formation of co-crystals and eutectics. IUCr J. 2015, 2, 341-351. [CrossRef]

44. Mukherjee, A. Building upon Supramolecular Synthons: Some Aspects of Crystal Engineering. Cryst. Growth Des. 2015, 15, 3076-3085. [CrossRef]

(C) 2020 by the authors. Licensee MDPI, Basel, Switzerland. This article is an open access article distributed under the terms and conditions of the Creative Commons Attribution (CC BY) license (http://creativecommons.org/licenses/by/4.0/). 